como-extrema-se-tornou-um-caso-de-sucesso-em-restauracao. Acesso em 15 de dezembro de 2020.

25. Conservador da Mantiqueira. Disponível em: https://conservadordamantiqueira.org/

26. Crouzeilles, R. et al. "There is hope for achieving ambitious Atlantic Forest restoration commitments". Perspectives in Ecology and Conservation, 17: 80-83, 2019.

27. Aliança pela Restauração na Amazônia: um pacto pela conservação da Amazônia brasileira. https://aliancaamazonia.org.br/

28. Aliança pela Restauração na Amazônia. Panorama e Caminhos para a Restauração de Paisagens Florestais na Amazônia. Position paper: 16p., 2020. Disponível em: https://aliancaamazonia.org.br/wp-content/uploads/2020/12/PAPER_ALIANCA_2020_01.pdf

29. A Rede de Sementes do Xingu é uma rede de trocas e encomendas de sementes de árvores e outras plantas nativas das regiões do Xingu, Araguaia e Teles Pires, que a partir de 2019 a passou a oferecer também serviços ligados à restauração de biomas como o Cerrado e a Floresta Amazônica. Disponível em: https://www.sementesdoxingu. org.br/site/

30. A Fundação Renova é a entidade responsável pela mobilização para a reparação dos danos causados pelo rompimento da barragem de Fundão, em Mariana (MG). Trata-se de uma organização sem fins lucrativos, resultado de um compromisso jurídico chamado Termo de Transação e Ajustamento de Conduta (TTAC). Disponível em: https:// www.fundacaorenova.org/

31. Kakabadse, Y.; Sánchez, L. E. "Cinco anos do desastre da barragem de rejeitos em Mariana: Olhando para o futuro". ((O)) eco, 10 de novembro de 2020. Disponível em: https://www.oeco.org.br/colunas/ colunistas-convidados/cinco-anos-do-desastre-da-barragem-de-rejeitos-em-mariana-olhando-para-o-futuro/. Acesso em 15 de dezembro de 2020.

32. Renovando paisagem. Disponível em: https://wribrasil.org.br/ pt/o-que-fazemos/projetos/renovando-paisagem. Acesso em 15 de dezembro de 2020.

33. Diálogo Florestal. Disponível em: https://dialogoflorestal.org.br/

34. Florestas do Futuro. Disponível em: https://www.sosma.org.br/iniciativa/florestas-do-futuro/

35. Klabin Sustentabilidade. Disponível em: https://klabin.com.br/sustentabilidade/

36. Suzano Sustentabilidade. Disponível em: https://www.suzano.com. br/sustentabilidade/

37. Vale Biodiversidade. Disponível em: http://www.vale.com/esg/pt/Paginas/Biodiversidade.aspx

38. Projeto Verena - promovendo a restauração e o reflorestamento com espécies nativas em larga escala no Brasil. Disponível em: https:// wribrasil.org.br/pt/projetoverena

\section{"EU ESCOLHO SEM VENENO": PARA A CONSTRUĢÕO DE SISTEMAS ALIMENTARES SUSTENTÁVEIS E SAUDÁVEIS}

\author{
Islandia Bezerra e Maria Alice Araújo Oliveira
}

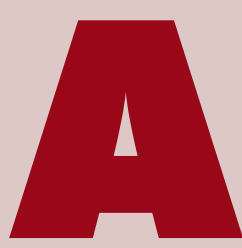

$s$ reflexōes acerca do atual sistema alimentar de produção industrial têm trazido algumas transformações no dia a dia de muitas pessoas em todo o planeta. Em que pese os argumentos políticos e econômicos de que o agroenegócio é o responsável pela manutenção da estabilidade da economia no país, esse mesmo setor pouco destaca os impactos ambientais, sociais, culturais e alimentares na sociedade contemporânea. O discurso que predomina é de que esse setor, sinônimo do sistema alimentar de produção industrial, com suas práticas produtivas caracterizadas pelo uso intensivo de agrotóxicos/veneno e destruição cada vez maior de florestas para expandir suas áreas de produção sobretudo de grãos e animais, é necessário para alimentar a população mundial.

Segundo o pesquisador Rob Wallace [1], a crise sanitária que estamos vivenciando globalmente é explicada a partir das práticas produtivas adotadas no atual sistema alimentar de produção industrial; ou seja, tanto as crises que já ocorreram, como as que estão em curso, e outras que estão por vir, todas elas possuem uma conexão direta com a expansão da agricultura intensiva (vegetal, como os grãos soja e milho e também cana-de-açúcar; e animal, como aves, suínos e bovinos). Somam-se a esse setor, com potencial igualmente destrutivo, sobretudo da natureza (e das culturas nos distintos territórios), outros ramos do setor como o plantio de tabaco (fumo), ou ainda o monocultivo de árvores exóticas, como pinus e eucalipto para a produção de madeira e celulose.

Porém, o questionamento que fazemos é: se este éo principal argumento, então, porque temos atualmente 690 milhöes de pessoas que padecem de fome no mundo? Este dado é da Organização das Naçōes Unidas para a Alimentação e a Agricultura (FAO na sigla em inglês) [3].

\section{A PRODUÇÃO E O CONSUMO QUE REPRODUZ E FORTALECE O SISTEMA} DOMINANTE Você já parou para pensar no que você come? Alguma vez se perguntou de onde vem esse alimento e/ou produto? Como foi feito (produzido, colhido, processado, distribuído, comercializado)? Qual a logística envolvida na distribuição (como é transportado, de caminhão, de navio, de aviāo)? E como veio parar no seu prato, mão, boca, corpo?

Vários estudos comprovam, cada vez mais, que o ato de se alimentar vem sendo induzido pelas diferentes estratégias das grandes empresas do setor (novos produtos no mercado, preços ainda mais acessíveis, propagandas nas mídias como TV, revistas, jornais, rádio 


\section{AGRONEGÓCIO = SISTEMA ALIMENTAR DE PRODUÇÃO INDUSTRIAL}

O agronegócio brasileiro se alinha a um modelo de desenvolvimento econômico pautado no plantio de monoculturas como soja, milho e cana-de-açúcar, com intensa utilização de agrotóxicos (venenos), e também na produção pecuária (frango, gado, suíno) cujo manejo baseia-se no uso de substâncias para o crescimento acelerado. Para aprofundar a leitura sobre esse tema, ver o capítulo "Sobre animais e peixes" do livro O negócio da comida de Esther Vivas Esteve [2]. Ainda sobre esse este setor, sabe-se que possui altos investimentos em tecnologias e seu principal objetivo é a exportação. É um sistema que contamina águas dos rios, mares, lagos, fontes/nascentes, solo e também nossa comida. Também é responsável por expulsar povos e comunidades tradicionais, povos originários e quilombolas, camponeses e camponesas dos seus territórios levando populações inteiras a migrarem. Ao longo das últimas décadas, esse sistema/modelo é o principal responsável pelas crises climáticas e vem colocando a natureza e a humanidade em risco.

Fonte: As autoras

e, mais recentemente, nas redes sociais) que fazem parte do sistema alimentar de produção industrial. Segundo Paula [4], são esses conglomerados do setor agroindustrial que envolve a produção-processamento-distribuição-comercialização que investem fortemente nessa imposição do consumo alimentar. E, cada vez mais, essa imposição se torna presente nas mesas e/ou nos pratos das pessoas, sendo estes chamados de "produtos comestíveis", ou seja, não são alimentos. Para uma compreensão mais visual, por favor, recomendamos que acesse o link (http://www.convergencealimentaire.info/ map.jpg), nesse esquema gráfico, temos uma ideia de como operam as indústrias do setor. Convém mencionar que se trata de uma imagem produzida em 2012, que certamente, hoje, em 2021 já deve ter sofrido alteraçōes.

O sistema de produção alimentar industrial faz uso das mais variadas dimensōes: de status (para referendar as desigualdades sociais e de classe econômica), da cultura (forjando preparaçōes prontas que trazem esse apelo) e sobretudo simbólica para fazer valer a sua imposição. Lembremos de uma marca famosa de bebida gaseificada (refrigerante) cuja mensagem para estimular o consumo é "abra a felicidade".

Esta marca, por exemplo, aliada à outra grande indústria do setor (que produz, processa, distribui e comercializa não apenas bebidas) são responsáveis por uma série de conflitos ao redor do mundo associados ao desmatamento de campos e florestas, à privatização de aquíferos e/ou de nascentes/fontes de água, à proibição do uso comum de territórios que possuem uma relação direta com a ma-

\section{PRODUTOS COMESTÍVEIS}

O Guia Alimentar para a População Brasileira [5] traz a classificação NOVA que agrupa os alimentos segundo a natureza, a finalidade e o grau de processamento: 1 . Alimentos in natura ou sem processamento; 2 . Alimentos in natura e minimamente processados; 3 . Alimentos processados; e 4. Alimentos ultraprocessados. Porém, neste texto será utilizado o termo "produtos comestíveis" para fazer referência aos ultraprocessados (e não alimentos), já que estes correspondem às formulações industriais produzidas integralmente ou em sua maioria de substâncias extraídas de alimentos (como gorduras e açúcares), ou derivadas de constituintes de alimentos (como gorduras hidrogenadas) ou ainda que são sintetizadas em laboratório com base em matérias orgânicas como petróleo e carvão, tais como os corantes, realçadores de sabor, aromatizantes e diferentes aditivos químicos. Alguns desses produtos comestíveis, por exemplo, possuem as mesmas substâncias presentes em material de limpeza e/ou maquiagem. Por isso, não dá para nominar de alimentos ultraprocessados e, sim, produtos comestíveis, pois estão aptos para o consumo humano (e animal), porém não são alimentos.

Fonte: As autoras. Adaptado do Guia Alimentar para a População Brasileira [5]

nutenção e reprodução da vida (como a prática extrativista de coleta de frutos silvestres ou mesmo a coleta de água para o consumo). São questôes dessa natureza que precisam ser consideradas também no ato cotidiano do comer.

É bem verdade que o ato de comer todos os dias - e se existem condiçôes de acesso físico aos alimentos, seja produzindo, trocando ou comprando, é possível comer mais de três vezes ao dia, fato que demarca tristemente nossa desigualdade social - é influenciado por uma infinidade de questōes. Nesse processo, o mais importante é compreender que o nosso ato de escolha individual - pelo que se come, quanto se come, onde se come e com quem se come - não é tão individual assim. Na verdade, é algo complexo e depende de diferentes fatores que vão desde os sociais, ambientais, econômicos até os culturais.

Emília Silva [6] afirma que "Não adianta pensar o consumo se não compreendemos a produção. Tampouco adianta pensar a produção do alimento sem levar em consideração todo o processo produtivo." Assim, é importante termos em mente que o atual sistema alimentar de produção industrial não é ético nem justo social, econômico, ambiental e culturalmente falando. Também podemos afirmar que não é saudável, pelo contrário, são várias as evidências científicas que comprovam a relação do consumo de determinados "produtos comestíveis" com o surgimento e/ou o agravamento de inúmeras doenças associadas à má alimentação. Para melhor compreender esta afirmativa, consultar Louzada e colaboradoras [7]. 
AGROECOLOGIA É AGIR PARA TRANSFORMAR Na contramão desse processo destrutivo da saúde (humana e ambiental), pode-se dizer que temos em curso várias açōes que vêm alterando a trajetória hegemônica desse sistema alimentar de produção industrial. Trata-se da emergência de um projeto multidimensional - a agroecologia - que rompe com os paradigmas desse desenvolvimento (econômico) que contamina, expulsa, explora (pessoas e natureza) e mata.

A partir desses apontamentos, é fundamental trazer para a prática cotidiana (assim como o ato de comer) as alternativas viáveis que temos para a criação e/ou o fortalecimento de sistemas alimentares sustentáveis e saudáveis. É sob esta ótica que Emma Siliprandi [9] destaca que a agroecologia propõe a construção de outro modo de vida, orientado pela noção de bem viver cujos valores éticos, de justiça ambiental e equidade social ganham relevo.

Alinham-se a esta constatação as palavras de Rubia Giordani, Islandia Bezerra e Mônica Anjos [10], quando afirmam que “... ao estabelecer uma estreita relação entre sociedade, natureza e cultura, orientada pela sustentabilidade da vida humana e dos ecossistemas, a agroecologia, em consonância com o princípio da soberania alimentar, promove um processo de ressignificação da comida, lançando luz sobre a interdependência entre os sistemas alimentares e os diferentes modos de viver, produzir e comer".

Para trazermos esta dimensão prática, serão tomados como exemplos dois projetos de extensão universitária desenvolvidos em realidades muito distintas - um na Universidade Federal do Paraná (UFPR), na região Sul do Brasil, e o outro na Universidade Federal de Alagoas (Ufal), na região Nordeste -, mas que abordam essas questôes (nada simples) de forma pedagógica e dialógica e que vêm promovendo mudanças significativas, tanto para quem produz, como para quem consome.

\section{ALIMENTE-SE: PRODUÇÃO E CONSUMO CONSCIENTE E SOLIDÁRIO} NA UFPR O projeto de extensão aliMENTE-SE: produção e consumo consciente e solidário [12], desenvolvido no âmbito do curso de nutrição da Universidade Federal do Paraná/UFPR, vem ao longo dos últimos três anos materializando ações específicas de extensão sob a perspectiva do diálogo de saberes [13], nos quais agricultores e agricultoras agroecológicas, docentes,

\section{AGROECOLOGIA}

Lilian Telles [8] define que a ciência agroecológica está vinculada a uma base social, representada pela diversidade sociocultural e política da agricultura familiar e camponesa, da agricultura urbana e de povos e comunidades tradicionais no Brasil, e deve ser compreendida por seu caráter multidimensional (político, cultural, técnico e científico). Por esse motivo, considera-se que a agroecologia é ao mesmo tempo ciência, prática e movimento discentes, comunidade universitária e externa vêm se envolvendo de forma ativa e integral.

Entre as ações desenvolvidas no projeto pode-se citar aquelas que ocorreram de forma mais frequente e sistemática como: 1 . as "Instalaçōes Pedagógicas Itinerantes-aliMENTE-SE", que promoveram açôes de troca de saberes (e sabores) entre famílias agricultoras agroecológicas com docentes, discentes e comunidade acadêmica e externa; 2. intercâmbio dias de campo "Integração Campo-Cidade - aliMENTE-atitudes", que ocorreram diretamente nas unidades de produção agroecológicas das agricultoras e agricultores e ainda no Centro Paranaense de Referência em Agroecologia/CPRA; e 3. formação de "Grupos de Consumo Conscientes e Solidários (GCCS) - aliMENTE-saúde" para as ações específicas referentes à comunidade que sustenta a agricultura (CSA).

Considerando que, atualmente, estamos vivendo uma situação jamais experimentada antes - a sociedade global passa pela experiência de conviver com uma crise ocasionada pela pandemia de covid-19 -, muitas das açôes propostas tiveram que ser adaptadas às normas sanitárias. A ação mais concreta e que segue com frequência semanal é a entrega de sacolas contendo alimentos agroecológicos. Certamente esta é a ação que potencializa processos transformadores no cotidiano alimentar tanto de quem produz, como de quem consome.

Antes de avançar nesta reflexão é fundamental fazer um breve histórico sobre essa alternativa real de transformação dos sistemas alimentares atuais para sistemas alimentares sustentáveis e saudáveis, partindo da hipótese de que sim, quem consome pode potencializar tais processos a partir do seu território, contando, obviamente, com a parceria de quem produz. Podemos nominar essa ação específica do projeto como sendo as CSAs. Porém, um ponto fundamental que precisa ser destacado é que, em geral, essa ação é conduzida por organizações da sociedade civil (do campo e das cidades) e possui uma estreita relação com as dimensōes políticas do produzir e do comer saudável.

O Japão foi o primeiro país a implementar esse modelo ainda nos anos de 1970 e o principal motivo dessa iniciativa tinha a ver, já naquela época, com o receio aos perigos provocados pelos agrotóxicos/venenos. A partir de então, em vários países surgiram ainda muito timidamente as CSAs [14]. Como mencionam Juliana Gonçalves e Thais Mascarenhas, por mais que esses grupos possuam nomenclaturas diferentes, na prática, a estratégia é a mesma: a construção de outro sistema alimentar que potencialize

\section{SOBERANIA ALIMENTAR NO COTIDIANO}

Por soberania alimentar, toma-se como referência aquelas práticas do dia a dia que incidem nas escolhas do que plantar (ou do que comprar), do que colher, como preparar e quando, quanto e como comer [11]. 
reflexōes-ações sobre o produzir e o comer. Nestas, as relações de solidariedade se expressam cotidianamente já que, segundo as autoras, em geral, os grupos “... são comprometidos a compartilhar riscos e benefícios, em diferentes graus e de diferentes formas, mas alinhados na perspectiva comum de contribuir para um novo paradigma nas relaçôes entre campo e cidade" [14].

O grupo vinculado a esse projeto de extensão foi denominado "aliMENTE-saúde". Percebe-se que o destaque ao termo "mente" traz o componente da tomada de consciência para o ato de se alimentar. No início do projeto, em julho de 2017, eram oito pessoas que acessavam as sacolas. Atualmente são pelo menos 60 sacolas entregues semanalmente, distribuídas em três grupos de consumo distintos, atendidos por duas famílias que produzem alimentos agroecológicos (um grupo do curso de nutrição, um grupo no curso de enfermagem e outro grupo que não faz parte do projeto de extensão de forma direta, mas que de alguma forma nos aproximou). Para cada pessoa (que representa um núcleo familiar de dois adultos e/ou dois adultos e pelo menos uma criança) que passa a compor o grupo, o motivo - em geral - é o mesmo: "Eu escolho sem veneno".

Os CSAs se espalharam de forma significativa ao longo dos últimos meses. O que se pode supor é que, em função das restriçōes sanitárias - que determinam o distanciamento físico e o isolamento social - esta foi (e segue sendo) a forma mais segura, eficaz e potente para seguirmos com os processos transformadores no âmbito dos sistemas alimentares em diferentes territórios, nos campos e nas cidades.

\section{COLHENDO BONS FRUTOS: NUTRIÇÃO E AGROECOLOGIA NA FANUT/}

UFAL O projeto de extensão "Colhendo Bons Frutos: Nutrição e Agroecologia", da Faculdade de Nutrição (Fanut) da Universidade Federal de Alagoas (Ufal), foi criado em 2014, tendo como objetivo fortalecer a inclusão socioeconômica de agricultores e agricultoras dos assentamentos Zumbi dos Palmares, Dom Helder Câmara e Flor do Bosque, localizados nos municípios de Branquinha, $\mathrm{Mu}$ rici e Messias (AL), respectivamente. Potencializar o cultivo e o beneficiamento dos alimentos agroecológicos, visando atender às demandas da feira agroecológica e orgânica da Ufal, e principalmente promover a alimentação saudável para a comunidade universitária e do entorno, foram os motivos que disparam a criação do projeto.

As feiras agroecológicas já ocorriam mensalmente na UFal desde 2010, a partir da organização de um grupo de mulheres camponesas que, em busca de autonomia financeira, criaram a Associação de Produtoras Agroecológicas da Zona da Mata de Alagoas (Aproagro) e a primeira organização de controle social (OCS) de Alagoas, possibilitando que sua produção fosse comercializada em feiras livres como alimentos orgânicos.

Em setembro de 2013, a feira, que era mensal, passou a ser semanal, sempre às quartas-feiras. Em abril de 2015, o grupo de camponeses e camponesas da feira orgânica da Ufal foi convidado pela Secretaria Municipal de Saúde de Maceió para participar de um evento alusivo ao Dia Mundial da Saúde. A partir de então surgiu a Feira Agroecológica e Orgânica da Praça do Centenário, que funciona semanalmente sempre aos domingos.

Ao longo dos últimos anos foram desenvolvidos diversos eventos e açōes de formação para quem produz alimentos agroecológicos, entre eles: cursos sobre agroecologia, introdução ao cooperativismo, acesso às políticas públicas de fortalecimento da agricultura familiar, apicultura, e sobre gestão e organização de feiras. Além dessas ações e em parceria a outros projetos que contavam com financiamento, foram adquiridos equipamentos para melhorar a infraestrutura e ordenamento das feiras, bem como materiais para irrigação e de sementes e mudas para estimular uma produção mais diversificada de legumes e hortaliças.

As ações de educação em saúde, com ênfase em alimentação e nutrição voltadas à comunidade universitária, mas também com o público consumidor das feiras foram desenvolvidas através de reuniōes e oficinas para identificação das demandas e de rodas de conversa realizadas nas próprias feiras. Nesses encontros, vários temas foram debatidos, tendo mais ênfase os impactos dos agrotóxicos na saúde (das pessoas e do ambiente), destacando assim a importância de fortalecermos as relações que se pautam na produção-consumo de alimentos agoecológicos.

Em um diagnóstico realizado por Pinho e colaboradores [15] que trata do perfil de quem consome os alimentos - nas duas feiras da Ufal e da Praça do Centenário - foi identificado que a maioria dos/ das participantes das feiras sabia a diferença entre alimentos orgânicos e convencionais (90\%). Quando se perguntou sobre o principal motivo para comprá-los, para $70 \%$ o que lhes motivou foi própria saúde, ou seja, "escolheram sem veneno". Mas, que de uma forma geral, esse mesmo público não reconhecia a importância de comprar o alimento diretamente de quem produz.

Estas constataçôes foram fundamentais para impulsionar processos pedagógicos de trocas de saberes, por isso, foram programados dias de vivências nos assentamentos, nos quais os camponeses e camponesas que fazem parte das feiras residem. O objetivo era materializar, de fato, a aproximação entre quem produz e quem consome e assim oportunizar conhecer e reconhecer as realidades dos modos de produção de alimentos agroecológicos, bem como as condições de vida daquelas pessoas que nos alimentam.

Com a pandemia, a feira da Ufal teve que ser temporariamente suspensa. Já a feira da Praça do Centenário permaneceu em plena atividade. Contudo, reitera-se que, para isso, foi necessário adotar uma série de medidas de proteção para evitar o contágio do vírus causador da covid-19 tais como o maior distanciamento entre bancas, disponibilização de álcool em gel, uso obrigatório e distribuição de máscaras. A princípio aquelas agricultoras e agricultores com idade mais avançada, ou com diagnóstico de doenças crônicas, ou mesmo àquelas que assumem a função de cuidadoras de outras vidas nas suas casas, se afastaram em definitivo e delegaram para outras pessoas membras de suas famílias a função de irem para a feira. 
Uma estratégia que foi fortemente acolhida tanto por quem produz, como por quem consome, foi adotar a prática das encomendas prévias e fazer o deslocamento até a praça apenas para pegar seus alimentos. Essa medida acabou dando mais agilidade ao processo, diminuído a circulação na praça e, ainda, reduzindo o tempo de exposição das/dos feirantes no espaço da praça. Esta ação de seguir com o consumo semanalmente se explica pela tomada de consciência e por reconhecerem o impacto político associado às suas escolhas alimentares. Mas, principalmente, por terem desenvolvido uma relação com quem produz que está baseada nos princípios da solidariedade e respeito - para com as pessoas e com a natureza -, pois de fato reconhecem os benefícios da produção agroecológica.

PARA NÃO CONCLUIR A partir dessas experiências, de uma coisa estamos certas: no centro deste debate está nossa comida! É a partir do que comemos que expressamos nossa existência (de ser, fazer e estar) em sociedade. Ontem, hoje e amanhã. Nossa cultura alimentar está ameaçada e a natureza está em risco! Portanto, nossa existência está em risco.

Nesse cenário pandêmico, mais pessoas estão tendo sua alimentação reduzida em quantidade e, especialmente, em qualidade. Enquanto o setor do agronegócio, o tal modelo onde impera uma produção alimentar industrial, segue com sua margem de lucro elevada sem se importar com os custos dessa produção para a saúde das pessoas e do ambiente. É a partir desta constatação que convidamos você leitor/leitora a somar nessa luta. E se perguntar: como é possível transformar uma realidade com a qual não estamos de acordo? Será que nossas práticas de comer cotidianamente influenciam no que se produz? Ou no que consumimos (ou, melhor, comemos)? Afirmamos que sim! Então, vamos nessa. Vamos lutar juntas e juntos por um sistema alimentar que produza saúde - de quem produz, de quem come e da natureza!

Islandia Bezerra é potiguara, mulher, mãe, nutricionista, professora da Faculdade de Nutrição/Fanut-Ufal. Pesquisadora, extensionista e atual presidenta da Associação Brasileira de AgroecologialABA-Agroecologia (2020-2021). islandia.bezerra@fanut.ufal.br

Maria Alice Araújo Oliveira é alagoana, mulher, mãe, nutricionista, professora da Faculdade de Nutriçāo/Fanut-Ufal, pesquisadora extensionista. alice.fanut@hotmail.com

\section{REFERÊNCIAS}

1. Wallace, R. Pandemia e agronegócio: doenças infecciosas, capitalismo e ciência. Edição: Elefante \& Igra Kniga. 2020.

2. Esteve, E. V. O negócio da comida: quem controla nossa alimentação? 10 ed. São Paulo: Expressão Popular, 2017.

3. FAO - Food and Agriculture Organization of the United Nations. The state of food security and nutrition in the world. Transforming food systems for affordable healthy diets. Rome, FAO, 2020.

4. Paula, N. M. Evolução do sistema agroalimentar mundial: contradições e desafios. Curitiba: CRV, 2017.
5. Brasil. Ministério da Saúde. Secretaria de Atenção à Saúde. Guia alimentar para a população brasileira. 2 ed. Brasília: Ministério da Saúde, 2014.

6. Silva, E. J. M. "Sistemas alimentares, soberania alimentar e a vida das mulheres: Elementos para o debate". In: Instituto Políticas Alternativas para o Cone-Sul - PACS. Mulheres e soberania alimentar: sementes e mundos possíveis. Rio de Janeiro, 2019.

7. Louzada, M. L. D. C.; Canella, D. S.; Jaime, P. C.; Monteiro, C. A. Alimentação e saúde: a fundamentação científica do guia alimentar para a população brasileira. São Paulo: Faculdade de Saúde Pública da USP, 2019.

8. Telles, L. "Desvelando a economia invisível das agricultoras agroecológicas: a experiência das mulheres de Barra do Turvo, SP". Dissertação (mestrado em extensão rural) - Universidade Federal de Viçosa, Viçosa, 2018.

9. Siliprandi, E. C. Mulheres e agroecologia: transformando o campo, as florestas e as pessoas. Rio de Janeiro: Editora UFRJ, 2015.

10. Giordani, R.; Bezerra, I.; Anjos, M. C. "Semeando agroecologia e coIhendo nutrição: Rumo ao bem e bom comer". In: Sambuichi, R. H. R.O.; Moura, I. F. D. O.; Mattos, L. M. D. O.; Ávila, M. L. D. O.; Spíndola, P. A. C. O.; Silva, A. P. M. D. O. (orgs.). A política nacional de agroecologia e produção orgânica no Brasil: uma trajetória de luta pelo desenvolvimento rural sustentável. Brasília: Ipea, 2017.

11. Furtado da Silva, A. C. G. F. S. "Mulheres e soberania alimentar [recurso eletrônico]: saberes agroecológicos entre assentadas". Dissertação (mestrado) - Programa de Pós-Graduação em Alimentação e Nutrição. Setor de Ciências da Saúde. Universidade Federal do Paraná. Curitiba, 2019.

12. É importante mencionar que o projeto foi desenvolvido entre 2017 e 2020, quando a autora Islandia Bezerra ainda compunha o quadro docente da UFPR. O projeto, porém, segue ativo e, cada vez mais, sendo ampliado.

13. Rezende, S. A. "Diálogo de saberes no encontro de culturas: o desafio da construção do conhecimento em agroecologia na educação do campo". Dissertação. Programa de Pós-Graduação em Educação, Setor de Educação, da Universidade Federal do Paraná. Curitiba, 2018.

14. Gonçalves, J.; Mascarenhas, T. “Grupos de consumo responsável no Brasil: aproximando consumidores e produtores em redes agroecológicas e solidárias". In: Abastecimento alimentar e mercados institucionais. / Org. Julian Perez-Cassarino ... [et al]. -- Chapecó: Ed. UFFS; Praia, Cabo Verde: UNICV, 2018.

15. Pinho, L. S.; Oliveira, M. A. A.; Menezes, R. C. E. Extensão em debate, Maceió, v.05, n.01, jan./jun. 2018. 